\title{
THE INCREASED SUSCEPTIBILITY TO HYDROGEN PEROXIDE OF THE (POST-)ISCHEMIC RAT HEART IS ASSOCIATED WITH THE MAGNITUDE OF THE LOW MOLECULAR WEIGHT IRON POOL
}

\author{
ARThur Voogd, Wim Sluiter, and Johan F. Koster \\ Department of Biochemistry, Erasmus University Rotterdam, The Netherlands
}

(Received 23 February 1993; Revised 29 June 1993; Accepted 2 September 1993)

\begin{abstract}
Recently we have shown that intracellular low molecular weight (LMW) iron increases during ischemia. It is hypothesized that this increase in LMW iron during ischemia underlies the reported hydrogen peroxide toxicity toward ischemic hearts. To investigate this hypothesis, rat hearts were subjected to $15 \mathrm{~min}$ of no-flow ischemia and reperfused with buffer saturated against $95 \% \mathrm{~N}_{2}$ and $5 \% \mathrm{CO}_{2}$ (anoxic reperfusion) for 7 min. Hearts were then switched to buffer saturated against $95 \% \mathrm{O}_{2}$ and $5 \% \mathrm{CO}_{2}$ (reoxygenation) to assess functional recovery. The cardiac function recovered to $80 \pm 7 \%$ of the preischemic value. When the anoxic reperfusion was applied in the presence of $10 \mu \mathrm{M}$ hydrogen peroxide, functional recovery after reoxygenation was $47 \pm 7 \%$. Hearts that were perfused with deferoxamine before ischemia and then subjected to ischemia and anoxic reperfusion in the presence of $10 \mu \mathrm{M}$ hydrogen peroxide recovered to $78 \pm 8 \%$. Immediate reoxygenation after ischemia led to only $45 \pm 6 \%$ recovery of function. During ischemia, LMW iron increased from $49 \pm 45$ to $183 \pm 45 \mathrm{pmol} / \mathrm{mg} \mathrm{protein}$ $(p<.05)$ and decreased to $58 \pm 38 \mathrm{pmol} / \mathrm{mg}$ protein $(p<.05)$ during the subsequent anoxic perfusion. Rat hearts preloaded with deferoxamine showed a slightly higher LMW iron content than normal $(85 \pm 23$ and $49 \pm 45 \mathrm{pmol} / \mathrm{mg}$ protein, respectively; n.s.), which showed a small, nonsignificant increase up to $136 \pm 42 \mathrm{pmol} / \mathrm{mg}$ protein after $15 \mathrm{~min}$ of ischemia. No significant changes were found in reduced and oxidized glutathione content and glutathione peroxidase or catalase activities under those conditions. Our results indicate that hydrogen peroxide toxicity is determined by the amount of catalytic iron in the LMW pool and not by a decrease in antioxidant defense capacity to hydrogen peroxide.
\end{abstract}

Keywords-Deferoxamine, Fenton reaction, Anoxic reperfusion, Free radicals

\section{INTRODUCTION}

In recent years it has been well established that reoxygenation of ischemic tissue leads to the generation of reactive oxygen species (ROS) ${ }^{1,2}$ It is likely that those ROS contribute to the reperfusion syndrome by damaging proteins, causing breakage of DNA strands, and initiating lipid peroxidation. ${ }^{2-4}$ In the presence of a catalytic transition metal such as iron, the toxicity of the ROS is tremendously increased by the conversion of hydrogen peroxide to the highly reactive hydroxyl radical. ${ }^{5}$

Under physiological conditions, iron is stored or contained in proteins in a noncatalytic form. ${ }^{6}$ Only a very small amount is thought to be present in a low molecular weight (LMW) pool, ${ }^{7,8}$ in a form that has been shown to catalyze hydroxyl radical formation. ${ }^{9-12}$ In

Address correspondence to: Johan F. Koster, Department of Biochemistry, Erasmus University Rotterdam, P.O. Box 1738, 3000 DR Rotterdam, The Netherlands. a recent study from our laboratory, ${ }^{13}$ it has been shown that intracellular LMW iron increases dramatically during ischemia in isolated rat hearts. In vitro, iron can be released from ferritin through a reductive mechanism, and this release is enhanced by a lower $\mathrm{pH} .^{14}$ Therefore, it has been proposed ${ }^{13}$ that this reallocation of iron during ischemia is caused by reducing equivalents arising during ischemia and that this is greatly enhanced by the acidification that occurs in the ischemic hearts. ${ }^{15}$

The role of iron in postischemic free radical toxicity has been substantiated by studies in which iron chelators that inhibit in vitro lipid peroxidation attenuate reperfusion injury in a variety of experimental animal models. ${ }^{16-19}$ However, this has never been studied in relation to the amount of catalytic iron in postischemic tissue. Shattock et al. ${ }^{20}$ have shown that ischemic rat hearts were much more sensitive to hydrogen peroxide than normoxic hearts. This raised the question of whether the rise in the intracellular LMW iron pool 
during ischemia as shown by us underlies the increased susceptibility toward hydrogen peroxide. To investigate this, we have studied hydrogen peroxide toxicity in postischemic rat hearts in relation to the LMW iron pool and the hydrogen peroxide defense system.

\section{MATERIALS AND METHODS}

\section{Animals and perfusion protocol}

Twelve- to fourteen-week-old male Wistar rats were used. After a brief anaesthesia with diethyl ether, the hearts were excised and placed in ice-cold Tyrode buffer. The hearts were cannulated through the aorta and perfused retrogradely according to Langendorff. ${ }^{21}$ Perfusions were carried out at $37^{\circ} \mathrm{C}$ with Tyrode buffer containing $128 \mathrm{mM} \mathrm{NaCl}, 4.7 \mathrm{mM} \mathrm{KCl}, 1.25 \mathrm{mM}$ $\mathrm{CaCl}_{2}, 20.2 \mathrm{mM} \mathrm{NaHCO}_{3}, 0.4 \mathrm{mM} \mathrm{NaH} \mathrm{PO}_{4}, 1 \mathrm{mM}$ $\mathrm{MgCl}_{2}$, and $11 \mathrm{mM}$ glucose, $\mathrm{pH} \mathrm{7.4.} \mathrm{The} \mathrm{buffer} \mathrm{was}$ saturated with $95 \% \mathrm{O}_{2}$ and $5 \% \quad \mathrm{CO}_{2}$. Tyrode buffer was made anoxic by saturation with $95 \% \mathrm{~N}_{2}$ and $5 \%$ $\mathrm{CO}_{2}$ for at least $1 \mathrm{~h}$. Perfusion pressure was held constant at $80 \mathrm{~cm}$ water pressure.

\section{Experimental design}

To assess hydrogen peroxide toxicity in the absence of superoxide, hearts were subjected to $15 \mathrm{~min}$ of warm no-flow ischemia and reperfused with anoxic buffer either with or without $10 \mu \mathrm{M}$ hydrogen peroxide for $7 \mathrm{~min}$. After this anoxic reperfusion, the hearts were perfused with oxygenated Tyrode buffer to assess functional recovery. The effect of iron chelation on this insult was investigated by preloading hearts with 50 $\mu \mathrm{M}$ deferoxamine during a 10 -minute perfusion immediately before ischemia and addition of $10 \mu \mathrm{M}$ hydrogen peroxide during the anoxic reperfusion period. During ischemia, the hearts were submerged in warm $\left(37^{\circ} \mathrm{C}\right)$ Tyrode buffer, which was gassed with $95 \% \mathrm{~N}_{2}$ and $5 \% \mathrm{CO}_{2}$. To assess hydrogen peroxide toxicity directly after anoxia, hearts were subjected to $15 \mathrm{~min}$ of anoxic perfusion, then switched to anoxic buffer containing $10 \mu \mathrm{M}$ hydrogen peroxide for $7 \mathrm{~min}$, and compared with hearts that were perfused with anoxic buffer for $22 \mathrm{~min}$.

Catalase, glutathione peroxidase, reduced glutathione, total glutathione, and LMW iron were determined in separate groups of hearts subjected to the appropriate perfusion protocol.

\section{Functional parameters}

Lactate dehydrogenase (LDH) release in the coronary effluent, as a measure of tissue damage, and coronary flow were determined as described earlier. ${ }^{18}$ Apex displacement was detected with a smooth muscle trans- ducer. Contractility, as a measure of cardiac work, was calculated as the product of apex-amplitude and apexfrequency, which were recorded every $30 \mathrm{~s}$. Data acquisition was started after the hearts had shown a stable contractility for $10 \mathrm{~min}$. The mean value of the contractility of each heart during $10 \mathrm{~min}$ before ischemia was set at $100 \%$, and subsequent performance was expressed as a percentage of preischemic contractility.

\section{Antioxidant, antioxidant enzymes, and $L M W$ iron determinations}

After the appropriate perfusions, hearts were immediately homogenized to a $10 \%$ homogenate in $100 \mathrm{mM}$ ice-cold Tris/ $\mathrm{HCl}, \mathrm{pH} 7.4$. The homogenate was centrifuged at $10.000 \mathrm{~g}$ for $15 \mathrm{~min}$.

Reduced glutathione was determined after protein precipitation by $5 \%$ trichloric acid of the resulting supernatant by reduction of 5,5-dithio-bis-2-nitrobenzoic acid (DTNB) measured as absorbance at $412 \mathrm{~nm}$. Total glutathione was determined by the reduction of DTNB in the presence of reduced nicotinamide adenine dinucleotide phosphate (NADPH) and glutathione reductase. $^{22}$

Glutathione peroxidase was determined as described elsewhere ${ }^{23}$ and expressed as units/mg protein ( 1 unit $=1 \mu \mathrm{mol} \mathrm{NADPH} / \mathrm{min}$ ). Protein concentration of the supernatant was determined using Biuret reagents with bovine serum albumin as standard. Catalase activity was assessed as the disappearance of hydrogen peroxide as determined at $240 \mathrm{~nm}$ at a hydrogen peroxide concentration between 7 and $9 \mathrm{mM}$ and expressed as micromoles per minute.

LMW iron was determined in the supernatant as described in detail elsewhere. ${ }^{13}$

\section{Statistics}

All data are presented as means \pm standard error of the mean (SEM). To evaluate differences between groups, one-way analysis of variance was performed on the data using the Stata release 2.0 (Computing Resource Centre, Los Angeles, CA).

\section{Chemicals}

Unstabilized hydrogen peroxide was obtained from Merck (Darmstadt, Germany; MOS selectipure, 12341) to avoid confounding effects of stabiliser substances. Deferoxamine Mesylate (deferoxamine) was obtained from Sigma Chemical Co. (St. Louis, MO). 

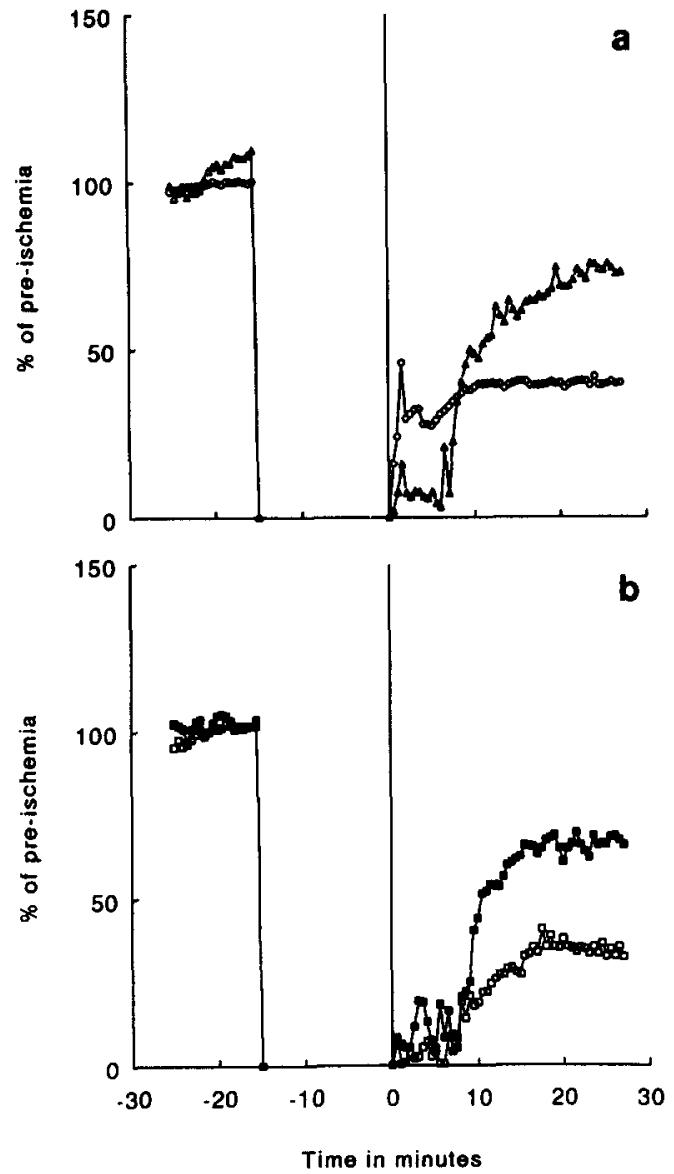

Fig. 1. (a) Effect of immediate reoxygenation on the recovery of contractility of hearts subjected to $15 \mathrm{~min}$ of ischemia (open circles) and the protective effect of a period of $7 \mathrm{~min}$ of anoxic reperfusion preceding reoxygenation (open triangles). (b) Effect of $10 \mu \mathrm{M}$ hydrogen peroxide administered during anoxic reperfusion after ischemia on the recovery of function upon reoxygenation (open squares) and the protective effect of preloading with deferoxamine (closed squares). Contractility is expressed as percentage of the preischemic value. A period of $15 \mathrm{~min}$ of ischemia preceded reperfusion, which starts at time zero. Standard errors are omitted for clarity $(n=6$ hearts in each group).

\section{RESULTS}

\section{Functional recovery and tissue damage}

To study the toxicity of hydrogen peroxide on the rat heart, the effect of this compound on cardiac function and tissue damage was established under various conditions. Rat hearts that were perfused with normoxic buffer containing $10 \mu \mathrm{M}$ hydrogen peroxide for 30 min suffered no loss of contractility or LDH release (results not shown).

Ischemia. Immediate reoxygenation of ischemic hearts impaired cardiac function ( $45 \pm 6 \%$ recovery; Fig. 1A), while a 7 -min period of anoxic perfusion preceding reoxygenation led to a much better $(80 \pm 7 \%)$ restoration of contractility (Fig. 1A). However, if 10 $\mu \mathrm{M}$ hydrogen peroxide was administered during this anoxic perfusion, a recovery of only $47 \pm 6 \%$ was found (Fig. 1B). To investigate whether this effect of hydrogen peroxide is mediated by an iron-dependent mechanism, the hearts were perfused with $50 \mu \mathrm{M}$ deferoxamine for $10 \mathrm{~min}$ before ischemia. Under those conditions, the hydrogen peroxide included in the anoxic buffer did not significantly decrease the recovery of the contractility ( $78 \pm 9 \%$, Fig. 1B).

The susceptibility of the Langendorff rat heart to hydrogen peroxide was also studied by the release of LDH in the coronary effluent as a parameter of tissue damage. Analysis of variance showed that hearts, reoxygenated immediately after $15 \mathrm{~min}$ of ischemia, released more LDH than hearts that were reperfused for the first $7 \mathrm{~min}$ after ischemia with anoxic buffer and then reoxygenated (Fig. $2 \mathrm{~A} ; p<.01$ ). However, if the
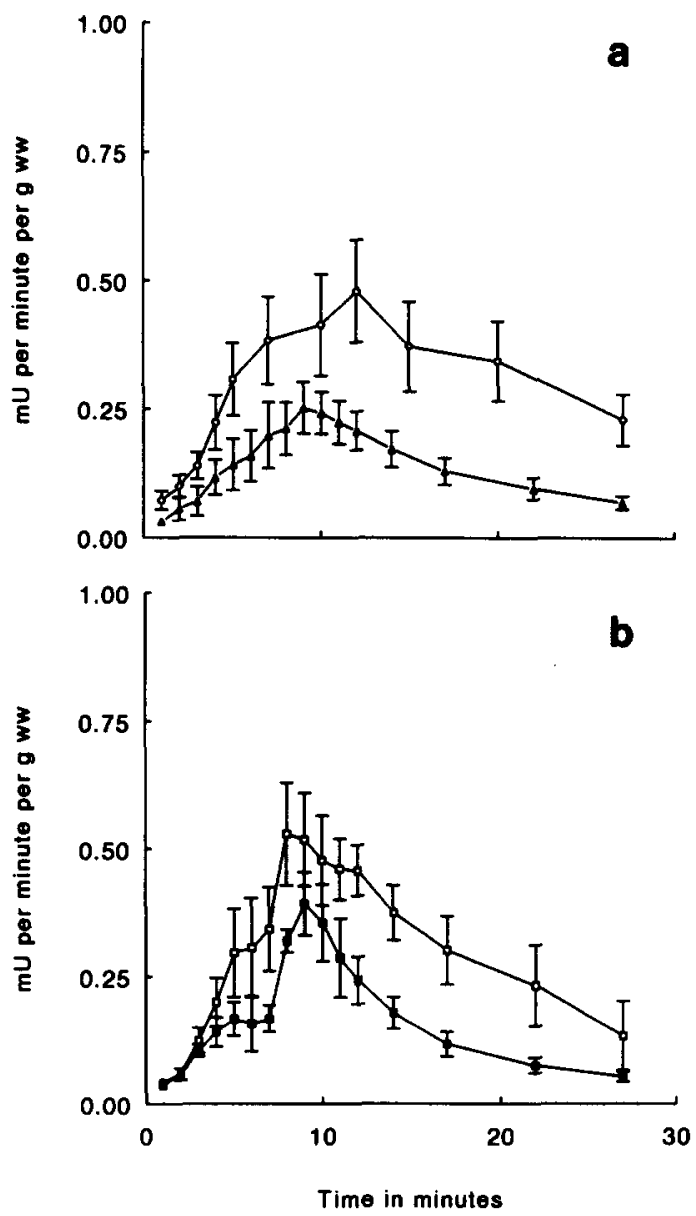

Fig. 2. (a) Effect of immediate reoxygenation on LDH release in the coronary effluent of hearts subjected to $15 \mathrm{~min}$ of ischemia (open circles) and the protective effect of $7 \mathrm{~min}$ of anoxic reperfusion after ischemia preceding reoxygenation (open triangles). (b) Effect of $10 \mu \mathrm{M}$ hydrogen peroxide administered during $7 \mathrm{~min}$ of anoxic reperfusion after ischemia on the LDH release upon reoxygenation (open squares) and the protective effect of preloading with deferoxamine (closed squares). Reperfusion starts at time zero. (Means \pm SEM, $n=6$ hearts in each group.) 


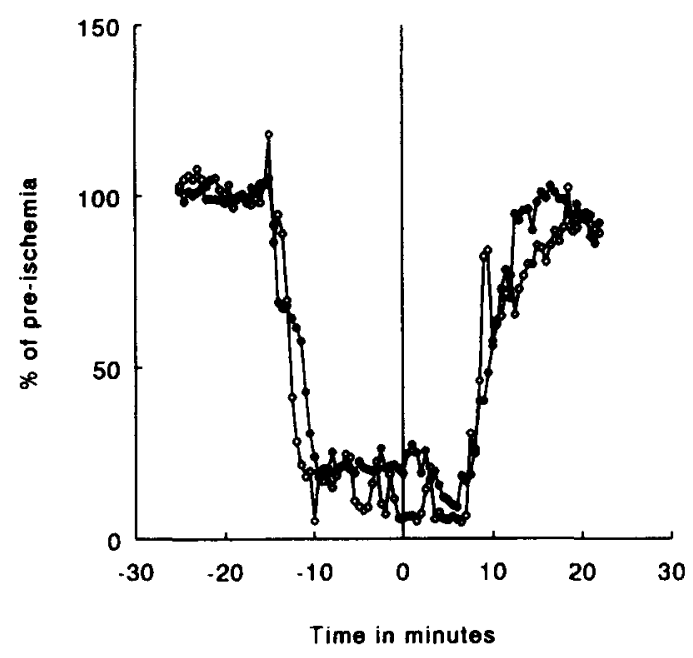

Fig. 3. Effect of reoxygenation on contractility after 22 min of anoxic perfusion of hearts perfused without (open circles) or with (closed circles) $10 \mu \mathrm{M}$ hydrogen peroxide present during the last $7 \mathrm{~min}$ of anoxia. A period of $15 \mathrm{~min}$ of anoxic perfusion (time $=-15$ to 0 ) preceded anoxic perfusion with or without hydrogen peroxide (time $=0$ to 7 ). After $7 \mathrm{~min}$, the hearts were reoxygenated (time $=7$ and onward). Means of five hearts per group; standard errors are omitted for clarity.

anoxic buffer contained $10 \mu \mathrm{M}$ hydrogen peroxide, the LDH in the coronary effluent increased significantly (Fig. 2B; $p<.01$ compared to anoxia without hydrogen peroxide, Fig. 2A). The increased release of LDH was prevented by preloading of the hearts with deferoxamine (Fig. 2B; $p<.01$, for the difference in the absence of deferoxamine).

Anoxia. To investigate whether the toxicity depends on a preceding period of ischemia, hydrogen peroxide toxicity was assessed after 15 min of anoxic perfusion. The results showed that hydrogen peroxide present during the last $7 \mathrm{~min}$ of a period of $22 \mathrm{~min}$ of anoxia did not impair the contractility of the reoxygenated hearts compared to the hearts subjected to anoxic perfusion without hydrogen peroxide (94 \pm 5 and $96 \pm$ $4 \%$, respectively, Fig. 3 ). In the coronary effluent from these hearts, very little LDH was detectable $(<0.05$ $\mathrm{mU} / \mathrm{g}$ wet weight/min). Furthermore, we have shown earlier that reoxygenation after anoxic perfusion did not lead to any loss of contractility and that LMW iron does not increase under those conditions. ${ }^{13}$

\section{Low molecular weight iron}

Because deferoxamine pretreatment abolished hydrogen peroxide toxicity after ischemia, the amount of iron in the LMW pool was determined under the vari- ous conditions (Fig. 4). During ischemia the amount of iron in the LMW pool increased from $49 \pm 16$ to $183 \pm 45 \mathrm{pmol} / \mathrm{mg}$ protein $(p<.05)$, confirming our earlier findings. ${ }^{13}$ Upon reperfusion with anoxic buffer in the presence or absence of hydrogen peroxide, the LMW iron pool returned to about normal values over the next $7 \mathrm{~min}(22 \pm 18$ and $59 \pm 29 \mathrm{pmol} / \mathrm{mg}$ protein, respectively; $p<.05$ ) and remained fairly constant after reoxygenation. Hearts preloaded with deferoxamine showed a slightly higher LMW iron content than normal $(85 \pm 23$ and $49 \pm 45 \mathrm{pmol} / \mathrm{mg}$ protein, respectively; n.s.), but ischemia did not lead to a significant increase of LMW iron in those hearts $(136 \pm 42 \mathrm{pmol} /$ $\mathrm{mg}$ protein after $15 \mathrm{~min}$; n.s.). Anoxic perfusion for 15 min did not cause a significant change in LMW iron, and neither did the additional $7 \mathrm{~min}$ of anoxic reperfusion in the presence of hydrogen peroxide. (61 $\pm 29,55 \pm 32$, and $42 \pm 25 \mathrm{pmol} / \mathrm{mg}$ protein respectively, n.s.).

\section{Antioxidant defense system}

Besides a role of LMW iron, it is possible that the increased susceptibility of the (post-)ischemic heart to hydrogen peroxide is caused by a decrease in the hydrogen peroxide metabolizing enzymes (i.e., catalase and glutathione peroxidase). A decrease of reduced glutathione, the substrate of the latter antioxidant enzyme, will also lead to impaired detoxification of hydrogen peroxide. Therefore, the activities of catalase and glutathione peroxidase, and the total glutathione and reduced glutathione content, were determined under the various conditions. Because hydrogen peroxide had no effect after a period of anoxia, these parameters were not determined in these hearts. Table 1 shows that the antioxidant defense system did not vary significantly between all groups (one-way analysis of variance, using the Bonferonni correction for multiple comparisons).

\section{DISCUSSION}

The main conclusion to be drawn from the present study is that the increased susceptibility to hydrogen peroxide of the postischemic heart is related to the amount of catalytic LMW iron and not due to a decrease in hydrogen peroxide metabolizing capacity.

Our data showed that a short period of anoxic reperfusion after ischemia causes a much better recovery of the contractility compared to immediate reoxygenation. Previously, the beneficial effect of hypoxic reperfusion was attributed to a decrease in the production of ROS during reoxygenation..$^{24}$ However, others have shown that after a short period of anoxic reperfusion, a burst of free radicals occurs during reoxygenation, 


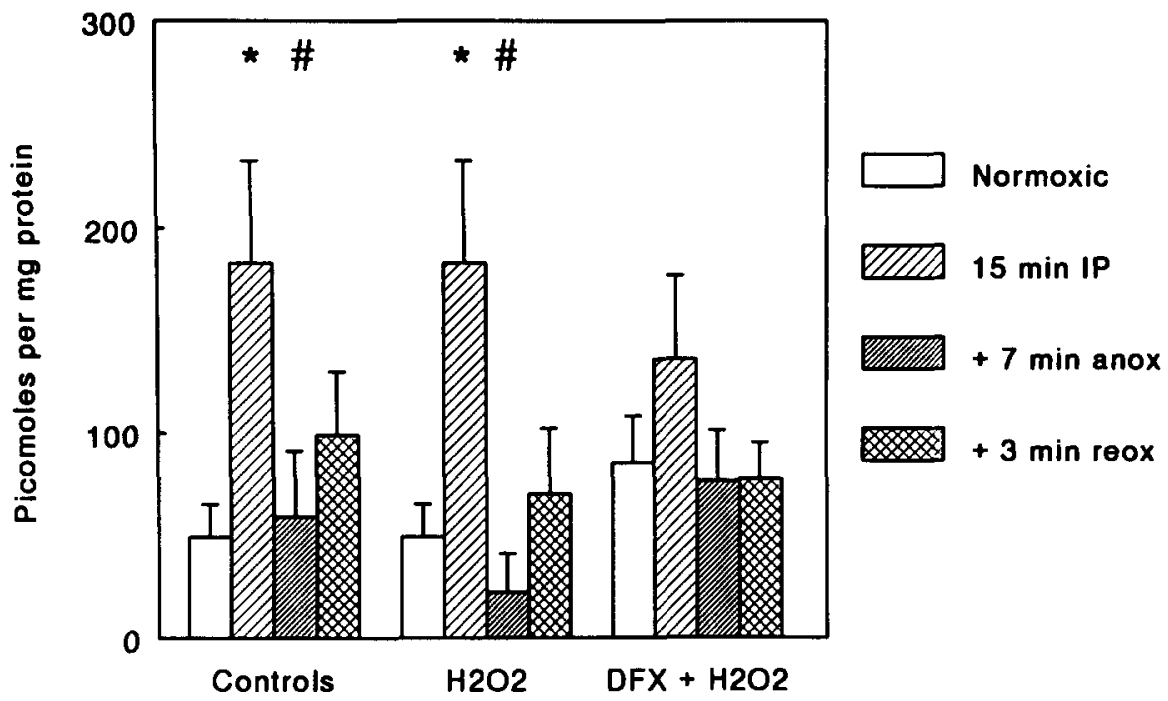

Fig. 4. The effect of anoxic reperfusion on LMW iron in hearts reperfused with anoxic Tyrode for the first 7 min after ischemia either without hydrogen peroxide (control), with $10 \mu \mathrm{M}$ hydrogen peroxide $\left(\mathrm{H}_{2} \mathrm{O}_{2}\right)$, or with hydrogen peroxide and deferoxamine pretreatment (DFX $+\mathrm{H}_{2} \mathrm{O}_{2}$ ). Hearts were homogenized as described after normoxic perfusion (normoxic), 15 min of ischemia (ischemic), $15 \mathrm{~min}$ of ischemia and $7 \mathrm{~min}$ anoxic reperfusion ( $+7 \mathrm{~min}$ anox), or after $15 \mathrm{~min}$ ischemia $+7 \mathrm{~min}$ anoxic reperfusion +3 min reoxygenation ( +3 min reox). Note that the first two groups in the control and the $\mathrm{H}_{2} \mathrm{O}_{2}$ group are identical. (* denotes $p<.05$ vs. normoxic hearts, \# denotes $p<.05$ vs. ischemic hearts in that group, means \pm SEM, $n=5$ in each group.)

which is of similar magnitude to the burst that occurs during immediate reoxygenation. In that study, no radicals were observed during the anoxic reperfusion period. ${ }^{25}$ In the present study, we have shown that during the anoxic reperfusion period the LMW iron pool, which was increased during ischemia, returned to values that did not differ from normoxic hearts. Apparently, under those conditions the amount of free iron became too low to catalyze the formation of hydroxyl radicals in sufficient amounts to cause tissue damage upon reoxygenation. This hypothesis is substantiated by our finding that hydrogen peroxide was only toxic when the LMW pool was increased. The presence of deferoxamine did not affect the magnitude of the LMW iron pool at the end of ischemia ( $183 \pm 45$ versus 136 $\pm 42 \mathrm{pmol} / \mathrm{mg}$ protein, $p=$ n.s.). During ischemia in the absence of deferoxamine, the released iron will be chelated to the natural chelators of the LMW pool, in

Table 1. Hydrogen Peroxide Specific Defenses in Rat Hearts Perfused with Normoxic Buffer (Normoxic) for 15 Min, after 15 Min of No Flow Ischemia (15' Ischemia), after 7 Min of Anoxic Reperfusion $\left(+7^{\prime}\right.$ $\mathrm{N}_{2}$ ), and after the Subsequent 3 Min of Reoxygenation $\left(+3^{\prime} \mathrm{O}_{2}\right)$

\begin{tabular}{|c|c|c|c|c|}
\hline & Normoxic & $15^{\prime}$ Ischemia & $+7 \min \mathrm{N}_{2}$ & $+3^{\prime} \mathrm{O}_{2}$ \\
\hline Glutathione peroxidase & & & \multicolumn{2}{|c|}{$\mu \mathrm{mol}$ NADPH per minute } \\
\hline Controls & $106.0 \pm 18.0$ & $172.0 \pm 44.0$ & $174.0 \pm 34.0$ & $168.0 \pm 40.0$ \\
\hline $\mathrm{H}_{2} \mathrm{O}_{2}$ & $106.0 \pm 18.0$ & $172.0 \pm 44.0$ & $186.0 \pm 38.0$ & $175.0 \pm 35.0$ \\
\hline $\mathrm{DFX}+\mathrm{H}_{2} \mathrm{O}_{2}$ & $164.0 \pm 45.0$ & $136.0 \pm 36.0$ & $195.0 \pm 65.0$ & $183.0 \pm 59.0$ \\
\hline Catalase & & & \multicolumn{2}{|c|}{$\mu \mathrm{mol} \mathrm{H}_{2} \mathrm{O}_{2}$ per minute } \\
\hline Controls & $20.9 \pm 2.4$ & $27.1 \pm 5.5$ & $24.1 \pm 4.0$ & $22.7 \pm$ \\
\hline $\mathrm{H}_{2} \mathrm{O}_{2}$ & $20.9 \pm 2.4$ & $27.1 \pm$ & $29.3 \pm 5.5$ & $26.2 \pm 5.2$ \\
\hline $\mathrm{DFX}+\mathrm{H}_{2} \mathrm{O}_{2}$ & $16.9 \pm 5.4$ & $19.5 \pm 4.7$ & $22.7 \pm 5.1$ & $27.6 \pm 4.0$ \\
\hline Reduced glutathione & & & \multicolumn{2}{|c|}{ nmol per mg protein } \\
\hline Controls & $16.6 \pm 3.2$ & $20.3 \pm$ & $25.5 \pm 5.2$ & $17.8 \pm$ \\
\hline $\mathrm{H}_{2} \mathrm{O}_{2}$ & $16.6 \pm 3.2$ & $20.3 \pm 5.4$ & $25.4 \pm 1.8$ & $16.2 \pm 3.1$ \\
\hline $\mathrm{DFX}+\mathrm{H}_{2} \mathrm{O}_{2}$ & $21.8 \pm 5.4$ & $18.5 \pm 4.2$ & $26.8 \pm 5.1$ & $18.1 \pm 1.3$ \\
\hline Total glutathione & & & \multicolumn{2}{|c|}{ nmol per mg protein } \\
\hline Controls & $14.4 \pm 3.6$ & $28.9 \pm 5.1$ & $24.4 \pm 3.9$ & $18.8 \pm$ \\
\hline $\mathrm{H}_{2} \mathrm{O}_{2}$ & $14.4 \pm 3.6$ & $28.9 \pm 5.1$ & $16.1 \pm 1.9$ & $15.8 \pm 5.1$ \\
\hline $\mathrm{DFX}+\mathrm{H}_{2} \mathrm{O}_{2}$ & $19.1 \pm 4.1$ & $16.8 \pm 2.4$ & $20.3 \pm 3.4$ & $10.5 \pm 1.2$ \\
\hline
\end{tabular}

Control hearts (control) were perfused with Tyrode only. $\mathrm{H}_{2} \mathrm{O}_{2}$ : Hearts that were reperfused with anoxic Tyrode containing $10 \mu \mathrm{M} \mathrm{H}_{2} \mathrm{O}_{2}$. DFX $+\mathrm{H}_{2} \mathrm{O}_{2}$ : Hearts that were perfused with normoxic Tyrode containing $50 \mu \mathrm{M}$ deferoxamine during $10 \mathrm{~min}$ before ischemia and reperfused with anoxic Tyrode containing $10 \mu \mathrm{M}$ $\mathrm{H}_{2} \mathrm{O}_{2}$. 
which form it is available to catalyse the Haber-Weiss reactions. However, in the presence of deferoxamine the released iron will be chelated as ferrioxamine, which does not catalyse these reactions. Smith et al. have shown that the protective effect of deferoxamine indeed depends on iron chelation, since the protection is lost when an equimolar amount of ferrioxamine is used. ${ }^{16}$ In the present study, hearts could cope with hydrogen peroxide immediately after ischemia only if the released iron had been rendered noncatalytic by the iron chelator deferoxamine. Therefore, we conclude that hydrogen peroxide is toxic after ischemia due to an iron-dependent mechanism.

How the drop in the LMW iron pool during anoxic reperfusion occurred is not known, but it is conceivable that the free iron was washed out. Calculation showed that approximately $10 \mathrm{nmol}$ of iron were lost. This is so little that it cannot be determined if diluted in the coronary effluent. Reuptake of iron by ferritin is not very likely because this process is oxygen dependent. ${ }^{26}$

Normally, hydrogen peroxide is detoxified effectively by the antioxidant enzymes catalase and glutathione peroxidase, but if the oxygen supply is suddenly increased after an ischemic period the formation of ROS may overwhelm the antioxidant enzyme system. Under such a condition and if accompanied by an increased amount of ferrous iron in the LMW iron pool, hydrogen peroxide is immediately converted to the highly reactive hydroxyl radical, leading to loss of cardiac function and tissue damage.

From a clinical point of view, our results indicate that it may be beneficial to flush an ischemic organ with anoxic buffer or venous blood before reoxygenation, because this could lead to normalized levels of LMW iron and attenuation of reperfusion injury without the need for pharmacological interventions.

\section{REFERENCES}

1. Zweier, J. L. Measurement of superoxide derived free radicals in the reperfused heart. J. Biol. Chem. 263:1353-1357; 1988.

2. McCord, J. Free radicals and myocardial ischemia: Overview and outlook. Free Radic. Biol. Med. 4:9-14; 1988.

3. Bolli, R. Oxygen derived free radicals in myocardial reperfusion injury: An overview. Cardiovasc. Drugs Ther. 5(Suppl. 2):249$269 ; 1991$.

4. Werns, S. W.; Lucchesi, B. R. Free radicals and ischemic tissue injury. Trends Pharmacol. Sci. 11:161-166; 1991.

5. Halliwel, B.; Gutteridge, J. M. C. Role of free radicals and catalytic metal ions in human disease: An overview. Methods Enzymol. 186:1-85; 1991.
6. Crichton, R. R.; Charloteaux-Wauters, M. Iron transport and storage. Eur. J. Biochem. 164:485-506; 1987.

7. Kozlov, A. V.; Yegorov, D. Y.; Vladimirov, Y. A.; Azizova. $O$. A. Intracellular free iron in liver tissue and liver homogenate: Studies with electron paramagnetic resonance on the formation of paramagnetic complexes with desferral and nitric oxide. Free Radic. Biol. Med. 13:9-16; 1991.

8. Fontecave, H.; Pierre, J. L. Iron metabolism: The low molecular mass iron pool. Biol. Metals 4:133-135; 1991.

9. Weaver, J.; Pollack, S. Low Mr iron isolated from guinea pig reticulocytes as AMP-Fe and ATP-Fe complexes. Biochem. $J$. 261:787-792; 1986.

10. Rush, J. D.; Maskos, Z.; Koppenol, W. H. Reactions of iron(II) nucleotide complexes with hydrogen peroxide. FEBS Lett. 261:121-123; 1990.

11. Floyd, R. A.; Lewis, C. A. Hydroxyl radical formation from hydrogen peroxide by ferrous iron nucleotide complexes. Biochemistry 22:2645-2649; 1983.

12. Mostert, L. J.; van Dorst, J. A. L. M.; Koster, J. F.; van Eijk, H. G.; Konthogiorges, G. J. Free radicals and cytotoxic effects of chelators and their iron complexes in the hepatocyte. Free Radic. Res. Comm. 3:379-388; 1987.

13. Voogd, A.; Sluiter, W.; van Eijk. H. G.; Koster, J. F. Low molecular weight iron and the oxygen paradox in isolated rat hearts. J. Clin. Invest. 90:2050-2055; 1992.

14. Funk, F.; Lenders, J. P.; Crichton, R. R.; Schneider, W. Reductive mobilisation of ferritin iron. Eur. J. Biochem. 152:167-172; 1985.

15. Jacobus, W. E.; Taylor, G. J.-I. V.: Hollis, D. P.; Nunnaly, R. L. Phosphorous nuclear magnetic resonance of perfused working rat hearts. Nature 1265:756-758; 1977.

16. Smith, J. K.; Garden, D. L.; Grisham, M. B.; Granger, D. N.; Korthuis, R. J. Role of iron in post ischemic microvascular injury. Am. J. Physiol. 256:H1472-H1477; 1989.

17. Xuekun, L.; Prasad, R.; Engelman, R.; Jones, R. M.; Das, D. K Role of iron in membrane phospholipid breakdown in ischemic perfused rat hearts. Am. J. Physiol. 259:H1 101-H1 107; 1991.

18. van der Kraaij, A. M. M.; Mostert, L. J.; van Eijk, H. G.; Koster, J. F. Iron load increases the susceptibility of rat hearts toward reperfusion damage. Protection by the anti oxidant $(+)$-cyanidanol-3 and deferoxamine. Circulation 78:442-449; 1988.

19. van der Kraaij, A. A. M.; van Eijk, H. G.; Koster, J. F. Prevention of post ischemic cardiac injury by the orally active iron chelator 1,2-dimethyl-3-hydroxy-4-pyridone (L1) and the antioxidant $(+)$-cyanidanol-3. Circulation 80:158-164; 1989.

20. Shattock, M. J.; Manning, A. S.; Hearse, D. J. Effects of hydrogenperoxide on cardiac function and post ischemic function recovery in the isolated working rat heart. Pharmacology 24:118122; 1982.

21. Langendorff, $O$. Untersuchungen am überlebenden Säugetierherzen. Plügers Archiv. Physiol. 61:225-241; 1895.

22. Baker, M. A.; Cerniglia, G. J.; Zaman, A. Microtiter plate assay for the measurement of glutathione and glutathione disulfide in large numbers of biological samples. Anal. Biochem. 190:360 $365 ; 1990$.

23. Lawrence, R. A.; Burk, R. F. Species, tissue and subcellular distribution of non Se dependent glutathione-peroxidase activity, J. Nutr. 108:211-215; 1978.

24. Korthuis, R. J.; Smith, J. K.; Carden, D. C. Hypoxic reperfusion attenuates postischemic microvascular injury. Am. J. Physiol. 256:H315-H319; 1989.

25. Garlick, P. B.; Davies, M. J.; Hearse, D. J.; Slater, T. F. Direct detection of free radicals in the reperfused rat heart using electron spin resonance spectroscopy. Circ. Res. 61:757-760; 1987.

26. Treffry, A.; Sowerby, J. M.; Harrison, P. M. Oxidant specificity in ferritin formation. FEBS Lett. 171:313-320; 1979. 